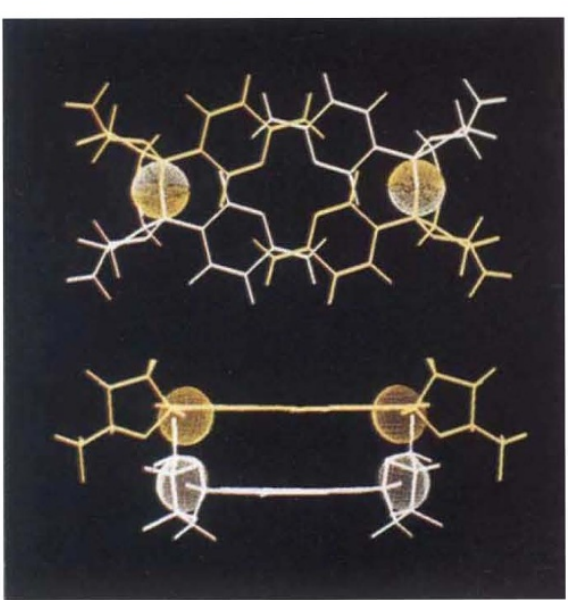

FIG. 3 Top, A view down the helix axis showing the stacking of adjacent $\mathrm{C} \cdot \mathrm{C}^{+}$base pairs originating from the two parallel-stranded duplexes (yellow and white) in the i-tetrad of $\mathrm{d}\left(\mathrm{TC}_{5}\right)$. The sugar $\mathrm{H}^{\prime}$ ' protons (dotted balls) on adjacent $\mathrm{C} \cdot \mathrm{C}^{+}$base pairs are directly over each other and would be expected to, and do, show strong NOEs to each other. Bottom, A view normal to the helix axis, once again showing the close proximity of sugar $\mathrm{H}^{\prime}$ protons on adjacent $\mathrm{C} \cdot \mathrm{C}^{+}$base pairs.

base pairs related by a helical rise and a rotation. The tetraplex structure has a pair of wide grooves (shortest phosphatephosphate separation between duplexes of $15.5 \AA$; Fig. 1, left) and a pair of narrow grooves (shortest phosphate-phosphate separation between duplexes of $4.9 \AA$; Fig. 1, right) with the backbone phosphates being in close proximity across the groove in the latter case.

Other features are extensive pair-wise sugar-phosphate backbone interactions with close van der Waals sugar-sugar contacts between the anti-parallel aligned strands from each of the $\mathrm{C} \cdot \mathrm{C}^{+}$parallelstranded duplexes across the minor groove in the tetraplex structure. In addition, adjacent $\mathrm{C} \cdot \mathrm{C}^{+}$base pairs whose long axes are orthogonal to each other, are stacked face-to-face (Fig. 3, top). The deoxycytidine $\mathrm{N}^{3}$ nitrogens are maximally separated, while the carbonyl and amide dipoles exhibit a reverse orientation between successive base pairs. The $\mathrm{H} 1{ }^{\prime}$ protons of adjacent base pairs are directly over each other (Fig. 3, top and bottom) and emphasize that the observed pattern of NOEs reflects the order of base-pair stacking rather than the covalent sequence.

In a companion paper ${ }^{16}$ the same group describes monitoring of the exchange characteristics of the imino and amino protons of the hemiprotonated $\mathrm{C} \cdot \mathrm{C}^{+}$base pairs in the $\mathrm{d}\left(\mathrm{TC}_{5}\right)$ tetraplex. Added catalyst has no effect on the imino proton exchange rates, reflecting the intrinsic exchange catalysis contributions ${ }^{17}$ by the acceptor atom in the $\mathrm{C} \cdot \mathrm{C}^{+}$base pair. These studies show that the base-pair opening kinetics for the i-tetrad are slow, with lifetimes of minutes. Such lifetimes are comparable to those reported for a few base pairs in the core of transfer RNA, but are distinctly longer than the few milliseconds observed for Watson-Crick base pairs in anti-parallel duplexes ${ }^{18}$. These long lifetimes must reflect the face-to-face and fully intercalated alignment of the hemiprotonated $\mathrm{C} \cdot \mathrm{C}^{+}$base pairs. Further, the absence of exchange broadening at the deoxycytidine amino protons accounts for the symmetry of the $\mathrm{C} \cdot \mathrm{C}^{+}$base pair because it means that the imino proton must switch between the $\mathrm{N}^{3}$ atoms of the deoxycytidines within the pair at a rate of over 80,000 per second.

The characterization of an i-tetrad structure provokes conjecture as to the role of this structural motif in biology. What, for instance, is the effect of supercoiling in inducing i-tetrad formation in repeating riboC $\mathrm{C}_{n}$ and deoxy $\mathrm{C}_{n}$ sequences? Can antibodies to the i-tetrad motif be generated, and can proteins that recognize and bind to it be isolated? Further, is it possible to generate i-tetrads at neutral $\mathrm{pH}$ through interactions with either nucleic acids or proteins? These and other questions remain to be investigated, and one eagerly awaits structure-function correlations involving this intriguing variation on nucleic-acid architecture. Lastly, speculation on the biological significance of the i-tetrad motif is prompted by the repetitive deoxycytidine stretches, such as deoxy $\left(\mathrm{C}_{4} \mathrm{~A}_{2}\right)$, which are found in telomeres. The deoxycytidines of four consecutive stretches could fold together into an i-tetrad motif, with the deoxyguanines of the partner strand forming a G-tetrad.

Dinshaw J. Patel is in the Program in Cellular Biochemistry and Biophysics, Memorial Sloan-Kettering Cancer Center, New York, New York 10021, USA.

1. Watson, J. D. \& Crick, F. H. C. Nature 171, 737-738 (1953).

2. Gehring, K. Leroy, J. L. \& Guéron, M. Nature 363 , 561-565 (1993)

3. Radhakrishnan, I., Patel, D. J., Veal, J. M. \& Gao, X J. Am. chem. Soc. 114, 6913 6915 (1992).

4. Radhakrishnan, I. \& Patel, D. J. J. Am. chem. Soc. 115 1615-1617 (1993)

5. Kang, C. H., Zhang, X., Ratliff, R., Mayzis, R. \& Rich, A. Nature 356, 126-131 (1992)

6. Wang, Y. etal. J. molec. Biol. 222, 819-832 (1991)

7. Smith, F. W. \& Feigon, J. Nature 356, 164-168 (1992)

8. Wang, Y. \& Patel, D. J. Biochemistry 31, 8112-8119 (1992)

9. Cheong, C. \& Moore, P. B. Biochemistry31, 84068414 (1992)

10. Wang, K. Y., McCurdy, S., Shea, R. G., Swaminathan, S. \& Bolton, P. H. Biochemistry 32, 1899-1904 (1993)

11. Drew, H., Takano, T., Tanaka, S., Itakura, K. \& Dickerson, R. E. Nature 286, 567-573(1980)

12. Wang. A. H. J. et al. Nature 282, 680-686 (1979)

13. Langridge, R. \& Rich. A. Nature 198, 725-728 (1963)

14. Cruse, W. B. et al. Biochemistry22, $1833-1839$ (1983)

15. Robinson, H., van der Marel, G. A., van Boom, J. H. \& Wang, A. H. J. Biochemistry 31, 10510-10517 (1992)

16. Leroy, J. L., Gehring, K., Kettani, A. \& Guéron, M. Biochemistry 23, 6019-6031(1993).

17. Guéron, M., Kochoyan, M. \& Leroy, J. L. Nature 328 , 89-92 (1987)

18. Guéron, M. \&Leroy, J. L. in Nucleic Acids and Molecular Biology Vol. 6 (eds Eckstein, F. \& Lilley, D. M.) 1-22 (Springer, New York, 1992).
DAEDALUS

\section{Cellular fabric}

\section{ONE of the neatest of natural} polymerizations is the condensation of glucose to cellulose. The reverse hydrolysis also goes very easily. Strong acid will do it, though cellulose-digesting bacteria and fungi use enzymes like cellulase. Daedalus points out that enzymes, however subtle, are simply catalysts. They must facilitate the forward and back reactions equally well. So he reckons you could make cellulose simply by adding cellulase to a solution of glucose. As fast as cellulose forms it would precipitate from the solution, driving the equilibrium to make more of it Growing plants seem to thicken their cell walls in just this way.

Cellulose by itself is fairly feeble stuff. It shows its real strength only when incorporated into some composite material. Wood, for example, is a composite of cellulose and lignin. Rot fungi digest the cellulose, leaving a shrunken lignin skeleton. So, says Daedalus, by immobilizing cellulase on rotten wood and treating it with glucose solution, you could reverse the process. The wood would accumulate internally distributed cellulose until it had regained its original size and strength. Brief heating could then denature the cellulase and stabilize the product.

This ingenious process should even work in situ. Decaying roofs or rotting floorboards could be restored with a dash of enzyme and a jug of syrup! On a smaller scale, the technique might also restore worn and threadbare garments. But Daedalus goes further. He recalls the wonderful strength and tenacity of nature's organic/inorganic composite materials. Bone, ivory, mother-of-pearl, all have an inorganic matrix filled with organic polymer. His process could induce this subtle microstructure in any solid porous structure.

So he is now filling a wide range of porous solids with cellulose. Chalk, concrete or plaster should be transformed into dense, tough, durable new engineering materials. Cellulose-metal composites would hold oil splendidly, and would damp out mechanical noise. Light and porous woods, such as balsa and spruce, could themselves be reinforced, upgrading them to the density and strength of teak or lignum vitae. Even cellulosereinforced cellulose should be possible. A cotton fabric stretched taut and filled with cellulose should give a sort of prestressed leather.

Daedalus's cellulose composites will transform engineering. They will even be welcomed by the green lobby. For, of course, they will be biodegradable. At the end of their long road, the fungi will lie in wait.

David Jones 